\title{
Author Correction: An inflammatory aging clock (iAge) based on deep learning tracks multimorbidity, immunosenescence, frailty and cardiovascular aging
}

Nazish Sayed (D, Yingxiang Huang, Khiem Nguyen, Zuzana Krejciova-Rajaniemi, Anissa P. Grawe, Tianxiang Gao, Robert Tibshirani, Trevor Hastie D, Ayelet Alpert, Lu Cui (1), Tatiana Kuznetsova, Yael Rosenberg-Hasson, Rita Ostan, Daniela Monti(D), Benoit Lehallier (D), Shai S. Shen-Orr (D), Holden T. Maecker, Cornelia L. Dekker (i), Tony Wyss-Coray (D), Claudio Franceschi, Vladimir Jojic, François Haddad, José G. Montoya, Joseph C. Wu, Mark M. Davis and David Furman (D)

Correction to: Nature Aging https://doi.org/10.1038/s43587-021-00082-y, published online 12 July 2021.

In the version of this Article originally published, the author Vladimir Jojic was mistakenly affiliated with 'Edifice Health Inc., San Mateo, CA, USA' instead of 'Calico Life Sciences L.L.C, South San Francisco, CA, USA'. This affiliation has now been added, and other footnotes renumbered accordingly, in all versions of the Article.

Published online: 26 July 2021

https://doi.org/10.1038/s43587-021-00102-X

() The Author(s), under exclusive licence to Springer Nature America, Inc. 2021 